\title{
Self-image of in-School Adolescents in Offa Local Government Area of Kwara State, Nigeria: Implications for Counselling Practices
}

\author{
Aminat Adeola Odebode \\ Dr., Department of Counsellor Education, Faculty of Education, University of Ilorin, \\ Ilorin, Nigeria, odebode.aa@unilorin.edu.ng
}

Many adolescents are anxious, depressed and have poor psychological well-being due to their self-image. This study therefore, investigated the self-image of inschool adolescents in Offa Local Government Area of Kwara State, Nigeria. The study also examined the influence of gender, age and class type on the respondents' perception. This study employed a descriptive survey method. A total of 400 secondary school students in Offa were selected through purposive and systematic sampling techniques. The participants responded to a researcherdesigned instrument entitled "Self-image Inventory" (SII). The validity of the instrument was done by team of experts. The reliability of the instrument was established using test re-test reliability method which yielded a coefficient of 0.76 . Data were analyzed using descriptive and inferential statistics. Analysis of Variance and t-test statistical tools were employed to test the hypotheses at 0.05 level of significance. Results showed that in-school adolescents in Offa LGA have negative self-image. Similarly, a significant difference existed based on class type. It is recommended among others that counsellors in schools should be allowed to perform their therapeutic roles so they can help in-school adolescents to develop positive self-image.

Keywords: self-image, in-school adolescents, Offa local government area, counselling practices, adolescent

\section{INTRODUCTION}

Self-image continues to be one of the most commonly researched concepts in social psychology. Teachers, Administrators and Parents are all concerned about students' selfimage. Its significance according to Smolak and Thompson (2009) is often exaggerated to the extent that negative/ low self-image is viewed as the causes of all agonies while positive self-image is viewed as source of happiness. Wang, Liang and Chen (2009) described self-image as pattern of perception admissible to one awareness which includes one's values, goals, feelings, knowledge and motivation.

Citation: Odebode, A. A. (2020). Self-image of in-School Adolescents in Offa Local Government Area of Kwara State, Nigeria: Implications for Counselling Practices. International Journal of Instruction, 13(1), 523-534. https://doi.org/10.29333/iji.2020.13134a 
According to Amburgey (2009), self-image is the idea one has of one's abilities, appearance and personality. A person's self-image is the mental picture, generally of a kind that is quite resistance to change, that depicts not only details that are potentially available to objective investigation by others (height, weight, hair color, gender, intelligent quotient etc.) (Rituparna \& Sonali, 2014) but also items that have been learned by that person about him/herself either from personal experience or by internalizing the judgments of others.

The image people see in the mirror may be a real or distorted view of who they really are. Based on the view of who they really are, they develop either a positive or a negative self-image. The strengths and weaknesses individual have internalized affect how they act daily. People continually take in information and evaluate themselves in multiple domains such as physical appearance (how do I look), performance (how am I doing) and relationship (how important am I) (Asmaa, 2015).

With a positive self-image, people recognize their assets and potentials while being realistic about their liabilities and limitations but with a negative self-image, people focus on their faults, weaknesses, failure and imperfections. Also a positive self-image can enhance people's physical, mental, social, emotional, and spiritual wellbeing while a negative self-image can decrease satisfaction and ability to function effectively in those areas. Self-image is not permanently fixed; part of individual's self-image is dynamic and changing. People learn to develop a healthier and more accurate view of themselves, thus challenging the distortions in the mirror. Usually, body image is associated with the individuals' consciousness of their body. Self-image change is a process occurring over a lifetime, a healthy self-image starts with learning to accept and love oneself (Hancock, Keast \& Ellis, 2017).

Many people feel bad about themselves from time to time. Feelings of low self-esteem may be triggered by being treated poorly by someone else recently or in the past, or by a person's own judgments of him or herself. However, low self-esteem is a constant companion for too many people, especially those who experience depression, anxiety, phobias, psychosis, delusional thinking, or who have an illness or a disability, such individual may go through life feeling bad about himself (Danis, MohD. Bahar, Md Isa \& Adilin, 2014). Usually, low self-esteem keeps individual from enjoying life, doing the things they want to do and working toward personal goals. For instance, one may begin to feel bad about oneself when insulted, when place under a lot of pressure at work, or when having a difficult time getting along with someone. Then such individual begins to give him/herself negative self-talk, like "I'm no good." This may make people feel so bad about themselves that they do things to hurt themselves or someone else, such as getting drunk, abusing drug or becoming aggressive; this could be worse for people who are adolescents.

The period of adolescence is a stage where specific changes occur that determines how the adolescent feels about himself. Adolescents are individuals who are between 10-19 years (Laura, Tilda \& Ronald, 2012). During this period an individual is been seen neither as a child nor as an adult. It could also be seen as transition from childhood to adulthood, involving physical, cognitive and social changes. Various authors viewed the 
term adolescence as a transitory period between childhood and adulthood (Bell \& Dittmar, 2011; Ciuluvica, Mitrofan \& Fulcheri, 2010; Laura, Tilda \& Ronald, 2012). Adolescence has been defined by Mitchell, Petrie, Greenleaf and Martin (2012) as a period when individual seeks to know whether he/she is acceptable like others or not. Mitchell et al., stated that adolescent at this stage, has an ideal self-image. According to Shipra, Shibhangna and Goldy (2009), culture, parents' child rearing practice, achievement related attributions and interaction with parents and teachers all influenced adolescent's self-image as they grow.

Rituparna and Sonali (2014) reported the lasting effects of early social relationship (parent-child relationship) on development of self-image and view childhood stage as a crucial time for self-image development. Although, Rituparna and Sonali assumed that hereditary and environment both shape individual self-image/self-esteem. Roger went further by explaining that adolescent with negative self-image sees their self-image as threat, deny it to consciousness and thereby set up a very wide gap between themselves which do not match their true feeling with the actual nature of their experience. Whereas, those adolescents with positive self-image are consistent with what they really think, feel and experience. Instead of being rigid, their self-image/self-esteem are flexible and change constantly as new experience occurs. Therefore, self-image refers to how an individual reflect on him/herself as a worthy person.

Amburgey (2009) stressed that apart from type of school setting, the socio-economic background, physical attractiveness, rate of maturation, experience, societal expectation, sex, parents-child relationship and child rearing method are some of the factors that affect individual adolescent self-image/self-esteem. In addition, some adolescents who receive poor/negative comments from family and friends, being a perfectionist, those who have inferiority complex, and those who are bullied among others could have negative self-image (White Swan Foundation, 2019).

Similarly, in many studies that have been conducted (Gatti, Ionio, Traficant \& Confalonieni, 2014; Hutchinson, Rapee \& Taylor, 2010), it was concluded that adolescent boys have higher self-esteem than adolescent girls and that females are more susceptible to self-image than male. In contrary to this, Laura, Tilda and Ronald (2012) submitted that sex differences in self-esteem/image are not likely to favour one sex than the other. The researcher believed that gender could have a significant influence in the self-image of adolescents with male have less perception of self. This could be because of girls growing rapidly than boys and the older one is, the more conscious one is about self. Furthermore, age could also affect body image; it has been concluded that adolescents who are in the early stage are more comfortable and satisfied with their body image than those in the latter stage (Ciuluvica, Mitrofan \& Fulcheri, 2010; Lithuania. Holmqvist, \& Frisén, 2012). It is on this basis that this study focused on the self-image of in-school adolescents in Offa Local Government Area of Kwara State, Nigeria and. gender, age and class type of the respondents as the moderating variables.

\section{Statement of the Problem}

Adolescents are usually confused with image of self; due to transition from childhood to adulthood, adolescents experience heightened emotion which affects their self- 
perception, body image and self-esteem. Poor self-image affects their academic achievement as a result of low self-esteem and low self-confidence which prevent the adolescent from making the best use of their educational opportunities and potentials. Poor self-image also affects interpersonal relationships due to sense of inferiority that usually accompanies it. Many of these adolescents cannot also open up on how they feel; they suffer silently as a result with deepened emotional trauma. In Offa LGA which is the locale of this study, many in-school adolescents were observed to be having challenges such as inability to express themselves appropriately, truancy, low academic performance, confusion among others. The researcher is then concerned that could these challenges be related to their self-image?

Many researchers have worked on adolescent's self-image and esteem. For instance, Shobhana and Rekha (2009) in Varanasi Distinct of Banaras Hindus University carried out an empirical study on adolescents 'self-image. The researcher came to conclusion that no significant difference was found with the regard to self-esteem of urban and rural adolescent; however significant differences were found in academic achievement of urban adolescents and academic achievement of rural adolescents. Also, Aryana (2010) worked on relationship between self-esteem and academic achievement amongst preuniversity students and came to conclusion that no significant difference was found in self-esteem between males and females. Shipra, Shubragna and Goldy (2009) carried out research on self-esteem among rural adolescent Girls in Kangra District of Himachant Praddech. The researchers concluded that there is a positive correlation between self-esteem and ages and education of girls, which means that girls living in nuclear families have a higher self-esteem compare to their counter part from extended family. Furthermore, Colquhoun, Bourne, Jamaica Constabulary Force (JCF) (2012) researched on self-esteem and academic performance of 4th graders in two elementary schools in Kingston and St. Andrew, Jamaica; the result showed statistical significant factors of self-esteem-academic performance, age of respondents, gender and parental behaviour. Despite many researches that have been conducted on self-image, the challenges that adolescents face do not appear to subside. Many of these adolescents cannot also open up on how they feel; they suffer silently as a result with deepened emotional trauma. Besides, to the best of the researcher's knowledge, no research has been carried out on self-image of in-school adolescents in Offa LGA of Kwara State. Therefore, there is need for this study.

\section{Research Question}

The question below was raised to guide the study;

What is the self-image of in-school adolescents in Offa Local Government Area of Kwara State?

\section{Research Hypotheses:}

The following hypotheses were formulated to guide the study

1. There is no significant difference in the self-image of in-school adolescents in Offa Local Government Area of Kwara State on the basis of gender. 
2. There is no significant difference in the self-image of in-school adolescents in Offa Local Government Area of Kwara State on the basis of class type.

3. There is no significant difference in the self-image of in-school adolescents in Offa Local Government Area of Kwara State on the basis of age.

\section{METHOD}

\section{Research Design}

The method employed in this research is the descriptive survey because it reports things the way they are. Milfs, Gabrielle and Elden (2010) explained that a descriptive research in education involves the collection of data for the purpose of describing existing situation. Furthermore, since the entire population cannot be considered in a study, the Descriptive survey method enables the researcher to draw sample from the entire population in which the data gathered from such can be generalized (Cohen, Manion \& Marison, 2011). Descriptive survey method was used because the research focused on self-image of in-school adolescents in Offa local government area of Kwara State (Sample) so that the result of the study can be generalized. Descriptive survey method was used for this research because the research focused on self-image of in-school adolescents in Offa local government area of Kwara State.

\section{Population}

The population for this research comprised all the senior secondary school students in Offa local Government Area of Kwara State. The target population for this study comprised all Senior Secondary School one students (SS1) of the selected schools in Offa local government. The number of secondary schools in Offa is 40 out of which 18 are public and 22 are private senior secondary schools. The raw estimate number of SS one students is 3,100 . Therefore, the researcher adopted a two-stage sampling procedure to select 400 respondents that participated in the study. At stage 1 , simple random sampling procedure was used to select 10 schools ( 5 public and 5 private schools to allow for fair representation of the secondary schools in Offa LGA) while at stage 2, systematic random sampling was used to select 40 students who are willing to participate in the study from each school which made a total number of 400 respondents that participated in the study.

\section{Instrumentation}

The instrument for this study is a inventory, titled Self-image Inventory (SII) which was adapted from Rosenberg Scale of Self-Esteem. It consists two sections (A \& B). Section A seeks respondent's bio data while section B consists of twenty (20) items on selfimage of in-school adolescents.

The format adopted for section B is the four-point rating type of Scale in which respondents were required to respond to using the responses format below:

VTM: Very true of me; TM: True of me; TM: Not true of me; NVTM: Not very true of me

In order to determine the content validity of the instrument, the researcher sought the expertise of three lecturers in the Department of Counsellor Education, University of 
Ilorin. These experts corrected and amended the items in the instrument to suit the purpose of the study. After all corrections were affected, these experts adjudged the instrument valid for the study. Test re-test technique was used to ascertain the reliability of the validated instrument using Pearson's Product Moment Correlation formula, a correlation coefficient of 0.76 was gotten, which implied that the instrument is reliable for the study. This conclusion is in line with the conclusion of Thomas (2013) that correlation coefficient between $0.50-1.00$ has high correlation and suitable for a research purpose. Using mean score $2.5(4+3+2+1 / 4)$, scores ranging from 2.5 and above indicated positive self-image while mean scores below 2.5 indicated negative self-image of in-school adolescents in Offa Local Government Area of Kwara State. According to Cohen, Manion and Marison (2011), when the four-point rating scale is adopted, mean score 2.5 can be used as a bench mark for making research decision. Percentages were used to analyze the demographic data (Section A of the instrument) while t-test and Analysis of Variance were used to test the formulated hypotheses at 0.05 level of significance.

\section{FINDINGS}

Research Question: What is the self-image of in-school adolescents in senior secondary schools in Offa Local Government Area of Kwara State?

Table 1

Mean and Rank Order of Self-image of In-school Adolescents in Offa Local Government Area of Kwara State

\begin{tabular}{llcc}
\hline Item No. & As far as I am concerned, I & Mean & Rank \\
\hline 3 & Do not bother what others say about me & 2.48 & $1 \mathrm{st}$ \\
1 & always satisfied with my physical appearance & 2.47 & $2 \mathrm{nd}$ \\
8 & Proud of my completion & 2.46 & $3 \mathrm{rd}$ \\
2 & believe I have great worth & 2.45 & 4 th \\
15 & often feel I can do almost everything I desire & 2.44 & 5 th \\
4 & Feel I have a number of good quality & 2.43 & 6 th \\
14 & Feel smart as others & 2.40 & 7 th \\
13 & Feel good about my relationship with others & 2.32 & 8 th \\
18 & Feel confident about my intellectual ability & 2.30 & 9 th \\
5 & Feel satisfied with my communication skill & 2.27 & 10 th \\
7 & Do not feel inferior to anyone & 2.27 & 10 th \\
9 & often feel I can succeed in any endeavour & 2.27 & 10 th \\
11 & am satisfied with my weight & 2.25 & 13 th \\
12 & am always pleased with my reaction to issues & 2.24 & 14 th \\
20 & think I can make decision on my own & 2.23 & 15 th \\
10 & am comfortable with new responsibilities & 2.20 & 16 th \\
6 & get over mistakes easily & 2.13 & 17 th \\
16 & am often comfortable in new situations & 2.12 & 18 th \\
17 & feel comfortable speaking in crowds & 2.00 & 19 th \\
19 & do not feel bad about criticism & 1.46 & 20 th \\
\hline
\end{tabular}

It shows on table 1 that all the items are below the mean score 2.5 therefore, it can be concluded that in-school adolescents have negative self-image. They believe that they are not satisfied with their physical appearance; they bother about what people say about 
them, they are not comfortable with new responsibilities, they feel bad about criticism etc.

Hypothesis One: There is no significant difference in the self-image of in-school adolescents in senior secondary schools in Offa Local Government Area of Kwara State on the basis of gender.

Table 2

Mean, Standard Deviation and T-Test Result on the Self-Image of In-School Adolescents in Offa Local Government Area of Kwara State, Nigeria

\begin{tabular}{llllllll}
\hline Gender & N & Mean & SD & df & Cal. t & Crit. t. & P \\
\hline Primary School & 246 & 66.92 & 6.98 & 398 & 0.43 & 1.96 & 0.65 \\
Secondary School & 154 & 66.47 & 7.26 & & & & \\
\hline
\end{tabular}

Table 2 shows that the calculated t-value of 0.43 is less than the critical t-value of 1.96 . This means that there is no significant difference in the self-image of in-school adolescents in senior secondary schools in Offa Local Government Area of Kwara State based on gender, thus, the hypothesis is not rejected.

Hypothesis Two: There is no significant difference in the self-image of in-school adolescents in senior secondary schools in Offa Local Government Area of Kwara State on the basis of age.

Table 3

Mean, Standard Deviation and T-Test Result on the Self-Image of In-School Adolescents in Offa Local Government Area of Kwara State, Nigeria based on Age

\begin{tabular}{llllllll}
\hline Age & $\mathrm{N}$ & Mean & SD & df & Cal. t & Crit. t. & P \\
\hline 9-13 years & 180 & 66.00 & 7.74 & 398 & 1.34 & 1.96 & 0.52 \\
14 years \& Above & 220 & 67.35 & 6.45 & & & & \\
\hline
\end{tabular}

Table 3 shows that the calculated t-value of 1.34 is less than the critical t-value of 1.96 . This means that there is no significant difference in the self-image of in-school adolescents in senior secondary schools in Offa Local Government Area of Kwara State based on age, thus, the hypothesis is not rejected.

Hypothesis Three: There is no significant difference in the self-image of in-school adolescents in senior secondary schools in Offa Local Government Area of Kwara State on the basis of class type.

Table 4

ANOVA Showing the Self-Image of In-School Adolescents in Offa Local Government Area of Kwara State on the basis of Class Type

\begin{tabular}{lcccccc}
\hline Source & df & SS & MS & Cal. t & Crit. t. & P \\
\hline Between Groups & 2 & 1505.600 & 752.80 & $35.31^{*}$ & 3.00 & 0.001 \\
Within groups & 397 & 8462.395 & 21.32 & & & \\
Total & 399 & 9967.955 & & & & \\
\hline
\end{tabular}

$* \mathrm{P}<0.05$

Table 4 shows that the calculated F-ratio of 35.31 is greater than the critical F-ratio of 3.00. This means there is significant difference in the self-image of in-school 
adolescents in senior secondary schools in Offa Local Government Area of Kwara State based on class type, thus, the hypothesis is rejected.

Table 5

Duncan Multiple Range Test (DMRT) Showing Direction Difference in the self-image of Respondents Based on Class Type

\begin{tabular}{lcccc}
\hline Class Type & Group & $\mathrm{N}$ & Mean & Duncan Groupings \\
\hline Commercial & 1 & 104 & 69.01 & $\mathrm{~A}$ \\
Arts & 2 & 198 & 66.82 & $\mathrm{~B}$ \\
Sciences & 3 & 98 & 65.37 & $\mathrm{C}$ \\
\hline
\end{tabular}

Table 5 presents the DMRT to show which of the variable that brought about the difference observed in the ANOVA table 4. The table shows that group A (with mean score of 69.01) differed significantly from groups B and C (with mean scores of 66.82 and 65.37 respectively), which differ slightly from each other. Thus, group A (Commercial) is responsible for the difference noticed in the self-image of in-school adolescents in senior secondary schools in Offa Local Government Area of Kwara State based on class type.

\section{DISCUSSION}

The finding shows that in-school adolescents in senior secondary schools in Offa Local Government Area of Kwara State have negative self-image. The finding shows that inschool adolescents in senior secondary schools in Offa Local Government Area of Kwara State have negative self-image. This finding means that in-school adolescents in senior secondary schools perceive themselves as having negative self-image. The finding further revealed that in-school adolescents are always not satisfied with their physical appearance; they bother about what people say about them, they are not comfortable with new responsibilities, they feel bad about criticism etc. This finding is in line with that of Shobhana and Rekha (2009) which showed that adolescents have negative self-image. Similarly, the finding of this study is consistent with that of Olushola (2002) which revealed that adolescents have negative self-image. This finding could be that the stage of adolescence which the respondents of this study are in, is full of bodily changes, different unfamiliar roles, wanting to be accepted in the society they live, and full of confusion. The adolescents if not adequately supported will have negative self-image.

The testing of hypothesis one revealed that there was no significant difference in the self-image of in-school adolescents in senior secondary schools in Offa Local Government Area of Kwara State based on gender. The testing of hypothesis one revealed that there was no significant difference in the self-image of in-school adolescents in senior secondary schools in Offa Local Government Area of Kwara State based on gender. This finding means that both male and female in-school adolescents in Offa LGA have low self-image. This also means that the gender of in-school adolescents in Offa LGA does not have any influence on the way they perceive their self-image. This finding is in support of the findings of Laura, Tilda and Ronald (2012) submitted that sex differences in self-esteem/image are not likely to favour one sex than the other. However, the finding of this study negates that of Gatti, Ionio, Traficant and 
Confalonieni (2014) and Hutchinson, Rapee and Taylor (2010) whose studies concluded that adolescent boys have higher self-esteem than adolescent girls and that females are more susceptible to self-image than male This may be due to the fact that both male and female in-school adolescents in Offa Local Government Area of Kwara State are in the same environment which influences their self-image in the same way.

The testing of hypothesis two showed that there was no significant difference in the selfimage of in-school adolescents in senior secondary schools in Offa Local Government Area of Kwara State based on age. The testing of hypothesis two showed that there was no significant difference in the self-image of in-school adolescents in senior secondary schools in Offa Local Government Area of Kwara State based on age. The meaning of this finding is that in-school adolescents in Offa LGA have low self-image, irrespective of their ages. This also means that the age of in-school adolescents in Offa LGA does not have any effect on the way they perceive their self-image. This finding is in support of the finding of Colquhoun, Bourne and Jamaica Constabulary Force (JCF) (2012) whose results showed statistically significant factors of self-esteem-academic performance, age of respondents. This study is however not in support of that of Ciuluvica, Mitrofan and Fulcheri (2010); Lithuania. Holmqvist, and Frisén, (2012) whose findings revealed that adolescents who are in the early stage are more comfortable and satisfied with their body image than those in the latter stage. This may be due to the fact that in-school adolescents in senior secondary schools in Offa Local Government Area of Kwara State are of the same age range; are all adolescents therefore could have negative self-image irrespective of their age.

The testing of hypothesis three revealed that there was significant difference in the selfimage of in-school adolescents in senior Secondary Schools in Offa Local Government Area of Kwara State based on class type. The testing of hypothesis three revealed that there was significant difference in the self-image of in-school adolescents in senior Secondary Schools in Offa Local Government Area of Kwara State based on class type. The interpretation of this finding is that the class type that the in-school adolescents in Offa LGA are has a significant effect on how they perceive their self-image. This also means that the fact that the in-school adolescents in Offa LGA are in either Arts, Science or Commercial class have influence on the way they perceive their self-image. Furthermore, the finding of this study revealed that in-school adolescents in senior secondary schools in Offa Local Government Area who are in Commercial class are responsible for the difference noticed in their self-image. The implication of this is that, in-school adolescents who are in commercial class have more negative self-image than those in other class types. This finding is in line with that of Amburgey (2009), Gatti, Ionio, Traficant and Confalonieni (2014) and Hutchinson, Rapee and Taylor (2010) whose findings showed significant differences in the self-image of adolescents on the basis of their school and class types. The finding further showed that the significant difference was brought about by students who are in commercial class. However, this difference might be because of high expectations placed on science students who will study courses like medicine, engineering, pharmacy etc. and the high grade required to be place in the class. This high expectation is not placed on students who are in 
commercial class; they are often relegated as those who are not as good as those in science class.

\section{CONCLUSION}

It was concluded that in-school adolescents in senior secondary schools perceived themselves as having negative self-image. This implies that they could be having inferiority complex. Similarly, gender and age did not influence the perception of selfimage among in-school adolescents in senior secondary schools in Offa Local Government Area of Kwara State. The class type of in-school adolescents in Offa LGA had influence on the perception of self-image with those in commercial class having more negative self-image than those in other class types

\section{COUNSELLING IMPLICATIONS}

Counselling service is an integral part of the school programme, due to the findings of this study, the school counsellors should ensure smooth transition of students from one academic level or from one class to another, identify learner's weaknesses, concern, learning disability, individual differences, strength as well as potentials.

It has been revealed that senior secondary school students in Offa Local Government Area of Kwara State have negative self-image. Therefore, counsellors in schools should help develop positive self-image among these students, counsellors should also carry out early diagnosis to determine students who have concern in one area or the other and provide remedial measures to solve their various concerns before it compounds and generate in to low self-image and low self-esteem. Similarly, particular attention must be paid to effective guidance and counselling service in schools to be able to assist students develop positive self-image.

In addition, according to the finding, class type has significant influence on senior secondary student's self-image. Because of this, counsellors should organize sequential and continuous career programme for the students which must include current and accurate occupational, educational and vocational information. This will go a long way in helping students to see that no occupation is better than the other and that all professions count. This could help boost the morale of these in-school adolescents. Counsellors should also motivate and encourage the students to pursue and excel in career of their choice so as for them not to feel inferior to anyone.

\section{RECOMMENDATIONS}

Due to the findings of this study, the following recommendations are made:

* Government should pay more attention to the need for effective guidance and counselling service in schools to be able to assist students develop positive selfimage.

* Government should also make provision for well-equipped counselling laboratory and other facilities required to set up an effective counselling center in schools. Government should also make provision for well-equipped counselling laboratory and other facilities required to set up an effective counselling centres in schools. 
There is the need for effective guidance and counselling service in schools to be able to assist students develop positive self-image.

* Counsellors in schools should be allowed to perform their therapeutic role such as helping in-school adolescents to develop positive self-image rather than being forced to teach.

* Counsellors should monitor students' academic achievement and academic concern, identify students with low self-concept and provide adequate counselling.

* Counsellors should teach the in-school adolescents problem solving skill and stress coping strategies to help them tackle their live challenges at adolescence and achieve their goals.

* Teachers should be sensitive to students' need, interest and concern. They should be careful when it comes to punishing students, because hostile punishment and scolding affect the adolescents' emotion and may lead to development of negative self-image.

* School administrators should see to the provision of conducive environment for students to learn as this would give them opportunity to explore their potentials.

* Parents should also make provision for their children's needs; they should always give them word of encouragement irrespective of their body image and must deviate from using abusive word that will kill their morale and lead to negative selfimage.

\section{REFERENCES}

Amburgey, R. K. (2009). An exploration of body image perception in an African American population (Unpublished master thesis). University of Pittsburgh, Pennsylvania.

Aryana, M. (2010). Relationship between self-esteem and academic achievement amongst pre-University students. Journal of Applied Sciences, 10, 2474-2477.

Asmaa, F. (2014). A study of self-esteem and academic achievement of adolescents in urban \& rural area (Unpublished master thesis). University of Malaysia, Kuala Lumpur.

Bell, B. T., \& Dittmar, H. (2011). Does media type matter? The role of identification in adolescent girls' media consumption and the impact of different thin-ideal media on body image. Sex Roles, 65, 478-490.

Ciuluvica, C. A., Mitrofan, N., \& Fulcheri, M. (2010). Emotions, self-esteem, and the perception of one's own body in the case of adolescents. Paper presented at the 12th Conference of the European Association for Research on Adolescence, Vilnius.

Cohen, L., Manion, D., \& Marison, H. (2011). Research methods in education. London: Routledge.

Colquhoun, L. K., Bourne, P. A., Jamaica Constabulary Force (JCF). (2012). Selfesteem and academic performance of 4th graders in two elementary schools in Kingston and St. Andrew, Jamaica. Asian Journal of Business Management, 4(1), 36-57. 
Danis, A. MohD. Bahar, W. Md Isa, K. A., \& Adilin, H. (2014). Body image perspectives among obese adolescents in rural environment setting. Procedia-Social and Behavioral Sciences, 153(16), 436-442.

Gatti, E., Ionio, C., Traficant, D., \& Confalonieni, E. (2014). I like my body; Therefore, I like myself: How body image influences self-esteem- A cross sectional study on Italian Adolescents. Europe's Journal of Psychology, 10(2), 15-28.

Hancock, K., \& Ellis, W. (2017). The impact of cyber dating abuse on self-esteem. The mediating role of emotional distress. J. of Psychosocial Res. on Cyberspace, 11(2): 2.

Holmqvist, K., \& Frisén, A. (2012). "I bet they aren't that perfect in reality": Appearance deals viewed from the perspective of adolescents with a positive body image. Body Image, 9(3), 3388-395.

Hutchinson, D. M., Rapee, R. M., \& Taylor, A. (2010). Body dissatisfaction and eating disturbances in early adolescence: A structural modeling investigation examining negative affect and peer factors. The Journal of Early Adolescence, 30(4), 4489-4517.

Laura, J. C., Tilda, F., \& Ronald, J. I. (2012). Social engagement in adolescence moderates the association between weight status and body image. Body Image, 9, 221226.

Mitchell, S. H., Petrie, T. A., Greenleaf, C. A., \& Martin, S. B. (2012). Moderators of the internalization-body dissatisfaction relationship in middle school girls. Body Image, 9(4), 4431-440.

Shobna, M., \& Rekha, B. (2009). Adolescents self-image. A paper presented to the Department of Psychology FSS, Banaras Hindu University, Varanasi.

Shipra, M., Shubhangna, T., \& Gold. N. (2009). Self-esteem among rural adolescent girls in Kangra district of Himachal Pradesh. Adolescents, 5, 23-34.

Smolak, L., \& Thompson, J. K. (2009). Body image, eating disorder and obesity in youth: Assessment, prevention and treatment. Washington DC: APA.

Rituparna, C., \& Sonali, D. (2014). Body image and its relation with the concept of physical self-image among adolescents and young adults. National Academy of Psychology. Retrieved from https://www.academia.edu/13706525/Body_Image_and_its_Relation_with_the_Concept _of_Physical_Self_Among_Adolescents_and_Young_Adults.

Swan Foundation (2019). Body image issues among adolescents. Retrieved from https://www.whiteswanfoundation.org/article/body-image-issues-among-adolescents/.

Thomas, G. (2013) How to do your research project. London: Sage.

Wang Y., Liang, H., \& Chen, X. (2009). Measured body mass index, body height perception, dissatisfaction and control practice in urban, low-income African American adolescent. BMC Public Health, 9, 183-194.

Zordão, O. P., Barbosa, A., Parisi, T. S., Grasseli, C. S. M., Nogueira, D. A., \& Silva, R. R. (2015). Associação da imagem corporal e transtornos alimentares em adolescentes de Minas Gerais (Brasil). Nutrición Clínica y Dietética Hospitalaria, 35(2), 48-56. 